\title{
Unplanned reoperation after radical gastrectomy for gastric cancer: causes, risk factors, and long-term prognostic influence
}

This article was published in the following Dove Press journal:

Therapeutics and Clinical Risk Management

\author{
Xueliang Zuo,** \\ Juan $\mathrm{Cai}^{2, *}$ \\ Zhiqiang Chen ${ }^{3, *}$ \\ Yao Zhang ${ }^{3}$ \\ Jian $W^{\prime}$ \\ Liangyu $\mathrm{Wu}^{4}$ \\ jinguo Wang'
}

'Department of Gastrointestinal Surgery, The First Affiliated Hospital, Yijishan Hospital of Wannan Medical College, Wuhu, China; ${ }^{2}$ Department of Oncology, The First Affiliated Hospital, Yijishan Hospital of Wannan Medical College, Wuhu, China; ${ }^{3}$ Hepatobiliary Center, The First Affiliated Hospital of Nanjing Medical University, Key Laboratory of Liver Transplantation, Chinese Academy of Medical Sciences, Nanjing, China; ${ }^{4}$ Department of General Surgery, Qingyang County People's Hospital, Qingyang, China

*These authors contributed equally to this work

\begin{abstract}
Purpose: Unplanned reoperation (URO) after radical gastrectomy for gastric cancer (GC) mostly results from serious postoperative complications. At present, there is still controversy over the predictive factors for URO. Our goal was to identify the risk factors for URO and to investigate its potential impact on long-term survival.
\end{abstract}

Patients and methods: We included 2,852 GC patients who underwent a gastrectomy. Multivariate logistic regression analyses were performed to determine the risk factors for URO. Patients were randomly selected from the non-URO group by 1:4 propensity score matching with multiple parameters with patients from the URO group. The survival disparity of 34 URO patients and 136 non-URO patients was examined using the Kaplan-Meier method and the multivariate Cox proportional hazard model.

Results: The incidence of URO was $1.4 \%(39 / 2,852)$. The primary cause of URO was intra-abdominal bleeding $(53.9 \%, 21 / 39)$. Multivariate logistic regression analyses revealed that male gender $(\mathrm{OR}=4.630,95 \% \mathrm{CI}=1.412-15.152, P=0.011)$, diabetes $(\mathrm{OR}=4.189$, $95 \% \mathrm{CI}=1.705-10.290, P=0.002)$, and preoperative hypoproteinemia $(\mathrm{OR}=2.305,95 \%$ $\mathrm{CI}=1.079-4.923, P=0.031)$ were independent risk factors for URO. With regard to early surgical outcomes, patients undergoing URO had a longer hospital stay $(P<0.001)$, higher incidence of postoperative complications $(P<0.001)$, and greater mortality $(P<0.001)$ compared with the non-URO group. No significant correlation was found between URO and cancer-specific survival in univariate $(P=0.275)$ and multivariate $(P=0.090)$ survival analyses.

Conclusion: Male gender, diabetes, and preoperative hypoproteinemia were suggested as independent risk factors for URO. URO was associated with longer hospital stay and increased perioperative mortality, but might not be correlated with long-term mortality.

Keywords: reoperation, stomach neoplasm, gastrectomy, postoperative complications

\section{Introduction}

Gastric cancer (GC) ranks fifth for cancer incidence and third for cancer deaths worldwide, ${ }^{1}$ and surgery is the most important therapeutic strategy in patients with resectable GC. China is classified as a high-incidence area for GC, with the third highest incidence and the second leading cause of death among all cancers. ${ }^{2}$ Despite the improvements of preoperative management and surgical technique, postoperative complications are still a common problem. Due to the intricacy of operative procedures, the incidence of complications after radical gastrectomy can be as high as $20 \%{ }^{3}$ Reportedly, $2 \%-10 \%$ patients with these complications need reoperation. ${ }^{4,5}$ Unplanned reoperation (URO) may result in psychological and physical problems, increase financial burden, prolong hospital stay, and even lead to death. ${ }^{6-9}$ Therefore, decreasing the
Correspondence: Jinguo Wang Department of Gastrointestinal Surgery, The First Affiliated Hospital, Yijishan Hospital of Wannan Medical College, 2 Zheshan West Road, Wuhu 241000, China

Tel +865535739558

Fax +865535738279

Email wangigwnmc@126.com 
incidence of postoperative complications and reoperation rate is of great importance in clinical practice.

Several studies reported the risk factors for GC postoperative complications..$^{3,10-13}$ Deguchi et al showed that pulmonary insufficiency and the duration of the operation are independent risk factors for anastomotic leakage. ${ }^{10}$ According to Kobayashi et al's study, dissection of the pancreas head area is an unfavorable predictor for postoperative pancreatic fistula after laparoscopic gastrectomy. ${ }^{13}$ However, substantial heterogeneity existed in previous studies and their findings were inconsistent. Furthermore, our knowledge of the impact of URO on long-term survival after radical gastrectomy is still limited. Thus, investigation into the relationship between URO and tumor prognosis is duly warranted.

The aim of this study is to systematically evaluate the risk factors for URO after radical gastrectomy and to explore the potential correlation between URO and long-term survival outcomes for patients. Our results may increase the awareness of URO among surgeons and prevent the occurrence of these undesirable postoperative events after surgery.

\section{Patients and methods}

\section{Patient population}

This study was designed as a retrospective analysis of GC patients treated with gastrectomy in the Department of Gastrointestinal Surgery, the First Affiliated Hospital of Wannan Medical College. A total of 2,992 patients undergoing gastrectomy for GC between January 2011 and December 2014 were enrolled. Exclusion criteria were as follows: 1) patients diagnosed with non-adenocarcinoma: squamous cell carcinoma $(\mathrm{n}=14)$, adenosquamous carcinoma $(n=4)$, and neuroendocrine carcinoma $(n=21)$; 2) patients who did not receive $D 2$ radical resection: openclose surgery $(n=27)$, non-R0 resection $(n=35)$, and postoperative American Joint Committee on Cancer (AJCC) stage IV ( $\mathrm{n}=17)$; and 3 ) patients undergoing emergency surgery $(n=22)$. Together, 2,852 patients were ultimately included for further analyses. Among them, 39 patients were termed as the URO group and 2,813 as the non-URO group (Figure 1). This study was conducted according to the ethical guidelines of the 1975 Declaration of Helsinki. The current research was reviewed and approved by the ethical review board of the First Affiliated Hospital of Wannan Medical College. Written informed consent was obtained from all patients.

\section{Data collection and definitions}

Patient information, medical history, concomitant diseases, primary surgical treatment, postoperative complications, clinical outcomes, and follow-up data were retrieved from the electronic database of the First Affiliated Hospital of

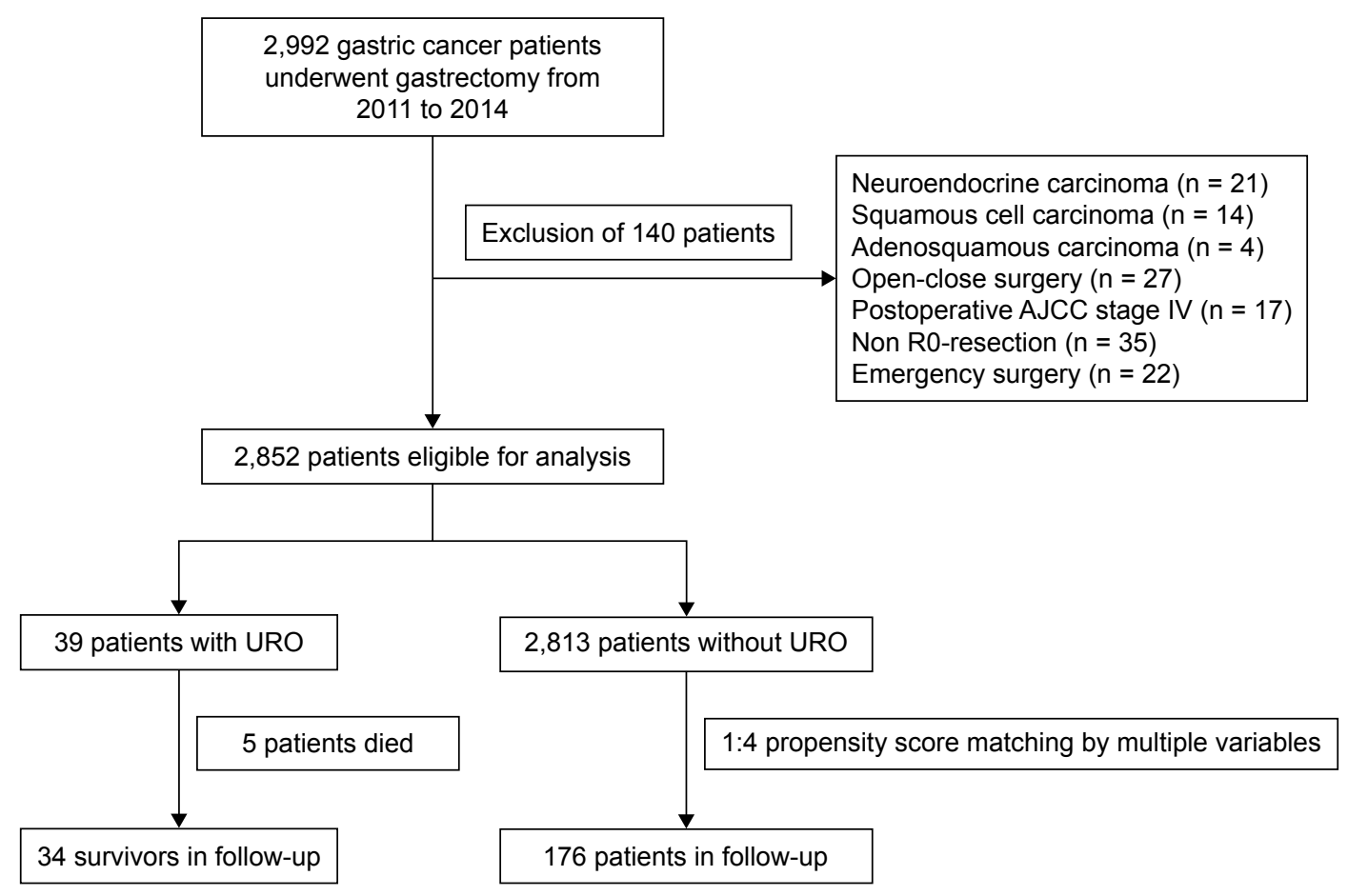

Figure I Flowchart of patient selection.

Abbreviations: AJCC, American Joint Committee on Cancer; URO, unplanned reoperation. 
Wannan Medical College. The postoperative pathological stages were determined according to the AJCC 8th Edition of Gastric Cancer TNM Staging. ${ }^{14}$

In this study, URO was defined as the status that the patient had to receive reoperation under general anesthesia and tracheal intubation due to severe postoperative complications caused by the initial gastrectomy for GC. Neoadjuvant chemotherapy was administered to patients with a preoperative staging $\mathrm{cT} 3 / 4$ or $\mathrm{cN}^{+}$, based on the decision after multidisciplinary discussion. ${ }^{15}$ Adjuvant combination chemotherapy was routinely implemented to all patients with postoperative staging II and III with oxaliplatin plus 5-FU/leucovorin (FOLFOX) or capecitabine (CapeOX) for 4-6 cycles. Cancer-specific survival refers to the time from the first gastrectomy to death of recurrence and metastasis.

\section{Operative techniques}

All operations were performed by experienced surgeons specializing in gastrointestinal surgery at our center. The surgeons had performed at least 100 D2 radical gastrectomies. Anticoagulants were discontinued 1 week before surgery. Depending on the location of the foci, total or partial gastrectomy was performed with D2 lymph node dissection, according to the new Japanese classifications and treatment guidelines for GC. ${ }^{16}$ The following methods were adopted for reconstruction after gastrectomy: Roux-en-Y reconstruction following total gastrectomy, Billroth-I or Billroth-II reconstruction following distal gastrectomy, and esophagogastrostomy following proximal gastrectomy.

\section{Follow-up}

As shown in Figure 1, five patients who died within 30 days afterURO were excluded from survival analysis. We followed-up all patients surviving the procedure of URO $(n=34)$ and 136 patients in the non-URO group who were randomly selected by propensity score matching based on the clinicopathological features, including postoperative AJCC stage, age, gender, body mass index, concomitant diseases, diabetes, preoperative hypoproteinemia, and preoperative anemia, with a ratio of 1:4. Follow-up data were obtained by telephone or email and the outpatient/inpatient clinical records. The last follow-up time was December 2017.

\section{Statistical analysis}

The risk factors included in the univariate analysis were age, gender, concomitant diseases, diabetes, preoperative hypoproteinemia, preoperative anemia, tumor size, type of surgical resection, type of reconstruction, surgical approach, combined organ resection, neoadjuvant chemotherapy, and postoperative AJCC stage. Categorical data were shown as percentages and were analyzed with Fisher's exact test. Continuous data were presented as mean \pm standard errors of the mean, and differences between groups were analyzed by the Mann-Whitney $U$ test. All clinical variables were included in a multivariate logistic regression model. Moreover, propensity score analysis was performed as a superior and more refined statistical method of adjusting for potential baseline confounding variables. ${ }^{17}$ The baseline risk profiles of the matched patients were compared to assure that no major differences in baseline patient characteristics persisted. The prognostic value of URO for cancer-specific survival was finally assessed using the Kaplan-Meier method and multivariate Cox proportional hazard model analysis after the propensity score matching. $\mathrm{R}$ statistical software was used to conduct propensity score matching, and all analyses were performed using the SPSS 24.0 software (IBM Corporation, Armonk, NY, USA). A twosided $P$-value $<0.05$ was considered statistically significant.

\section{Results}

\section{Severe complications, primary causes, and management of URO}

We included 2,104 males and 748 females in this study. The mean age was $65.0 \pm 9.3$ years. Among the enrolled 2,852 patients, 39 cases (mean age: $62.1 \pm 10.1$ years) underwent URO, including 36 males and three females. The primary causes of URO were intra-abdominal bleeding $(15 / 39,38.5 \%)$, anastomotic leakage and intra-abdominal bleeding $(6 / 39,15.4 \%)$, incision dehiscence $(6 / 39,15.4 \%)$, intestinal obstruction $(4 / 39,10.2 \%)$, anastomotic leakage and intra-abdominal infection $(3 / 39,7.7 \%)$, jejunal perforation $(3 / 39,7.7 \%)$, and anastomotic bleeding $(2 / 39,5.1 \%)$.

The total incidence of URO resulting from intra-abdominal bleeding was $53.9 \%$ (21/39), and all bleeding cases were confirmed by arterial angiography or open surgery. Splenic area was the most common site of bleeding found during the reoperation $(5 / 21,23.8 \%)$. The primary causes of bleeding were associated with operative technique failure (13/21, $61.9 \%)$ and anastomotic leakage $(6 / 21,28.6 \%)$. Regarding the treatment of bleeding caused by anastomotic leakage, suturing the bleeding vessels and adequate abdominal drainage were necessary. Among the 21 patients with postoperative bleeding, 18 patients recovered after URO, while three patients died. Eight patients required a third operation due to re-bleeding. The detailed causes, treatments, and outcomes of URO patients with intra-abdominal bleeding are presented in Table 1. 
Table I Intra-abdominal bleeding position, cause, and treatment

\begin{tabular}{|c|c|c|c|c|c|}
\hline Position & Cases (\%) & $\begin{array}{l}\text { Mean } \\
\text { interval days }\end{array}$ & Cause & Treatment & Outcome \\
\hline Splenic artery & $4(19.0)$ & 22.5 & $\begin{array}{l}\text { Technical failure or } \\
\text { anastomotic leakage }\end{array}$ & $\begin{array}{l}\text { Suture, TAE } \\
\text { Suture and abdominal drainage }\end{array}$ & $\begin{array}{l}\text { Two patients died of } \\
\text { re-bleeding, two recovered }\end{array}$ \\
\hline $\begin{array}{l}\text { Superior pancreatic } \\
\text { vessels }\end{array}$ & $3(14.2)$ & 0.2 & Technical failure & Suture & $\begin{array}{l}\text { One patient re-bled, two } \\
\text { recovered }\end{array}$ \\
\hline $\begin{array}{l}\text { Right gastroepiploic } \\
\text { vessels }\end{array}$ & $2(9.5)$ & 9.8 & $\begin{array}{l}\text { Technical failure or } \\
\text { anastomotic leakage }\end{array}$ & $\begin{array}{l}\text { Suture } \\
\text { Suture and abdominal drainage }\end{array}$ & $\begin{array}{l}\text { One patient re-bled, the } \\
\text { other recovered }\end{array}$ \\
\hline Gastroduodenal artery & $2(9.5)$ & 9.5 & Anastomotic leakage & Suture and abdominal drainage & $\begin{array}{l}\text { One patient died of } \\
\text { re-bleeding, one recovered }\end{array}$ \\
\hline $\begin{array}{l}\text { Transverse mesocolon } \\
\text { vessels }\end{array}$ & I (4.8) & 0.8 & Technical failure & Suture & Recovered \\
\hline Right gastric artery & I (4.8) & 19 & Abdominal infection & Suture and abdominal drainage & Re-bled \\
\hline Spleen & I (4.8) & 4 & Technical failure & Splenectomy & Recovered \\
\hline Abdominal wall muscle & $\mathrm{I}(4.8)$ & 8 & Technical failure & Suture & Recovered \\
\hline Gastric wall & I (4.8) & 20 & Gastric necrosis & Gastrectomy & Recovered \\
\hline Unidentified & $5(23.8)$ & 4.5 & Technical failure & Suture & $\begin{array}{l}\text { Two patients re-bled, } \\
\text { three recovered }\end{array}$ \\
\hline Total & $21(100.0)$ & 9.7 & - & - & - \\
\hline
\end{tabular}

Note: Mean interval days: the time between the first operation and the unplanned reoperation.

Abbreviation: TAE, transcatheter arterial embolization.

\section{Risk factors for URO}

As shown in Table 2, three factors including male gender $(P=0.005)$, diabetes $(P=0.010)$, and preoperative hypoproteinemia $(P=0.035)$ were closely correlated with URO. Furthermore, the multivariate analysis using logistic regression demonstrated that male gender $(\mathrm{OR}=4.630,95 \%$ $\mathrm{CI}=1.412-15.152, P=0.011)$, diabetes $(\mathrm{OR}=4.189,95 \%$ $\mathrm{CI}=1.705-10.290, P=0.002)$, and preoperative hypoproteinemia $(\mathrm{OR}=2.305,95 \% \mathrm{CI}=1.079-4.923, P=0.031)$ were independent risk factors for URO (Table 3 ).

\section{Early surgical outcomes of the URO patients}

After reoperation, 19 patients developed postoperative complications, including re-bleeding, pulmonary infection, ileus, and incision infection. The incidence of postoperative complications after URO was $48.7 \%(19 / 39)$, whereas the incidence was $14.0 \%(396 / 2,813)$ in the non-URO group. Furthermore, patients with URO had a significantly increased time of hospital stay $(35.03 \pm 14.85$ vs $15.52 \pm 6.16$ days, $P<0.001$ ). Compared with the non-URO group (six out of the 2,813 patients), five out of 39 patients with URO died of disseminated intravascular coagulation (DIC) or multiple organ dysfunction syndrome during hospitalization. The mortality was $12.8 \%(5 / 39)$ in the URO group and $0.2 \%(6 / 2,813)$ in the non-URO group $(P<0.001)$. Together, URO was correlated with prolonged hospital stay, increased in-hospital complications, and higher perioperative mortality (Table 4).

\section{Assessment of URO as a prognostic factor for long-term survival}

A total of 34 URO patients and 136 propensity matched patients without URO were included in the long-term follow-up analysis. The propensity score in patients who underwent URO was $0.028 \pm 0.005$, compared with $0.030 \pm 0.004$ in those who did not undergo URO $(P=0.782)$, indicating no significant bias in the patient characteristics. The median follow-up time was 56 months. The 1 - and 3-year cancer-specific survival rates of patients with URO were $88.23 \%$ (30/34) and 47.1\% (16/34), and 97.8\% (133/136) and $56.6 \%(77 / 136)$ in patients without URO. According to the univariate and multivariate survival analyses, URO was not associated with cancer-specific survival $(P=0.275)$ (Figure 2 and Table 5). In addition, AJCC stage (HR $=7.004$, 95\% CI $=2.130-23.034, P=0.001)$ and preoperative hypoproteinemia $(\mathrm{HR}=1.831,95 \% \mathrm{CI}=1.126-2.978, P=0.015)$ significantly affected the cancer-specific survival in this study. Taken together, URO might not be correlated with long-term cancer-specific survival of GC patients.

\section{Discussion}

Reoperation following surgery is correlated with higher morbidity, mortality, and cost to the health care system. ${ }^{18}$ The URO rate, recognized as a compelling evaluation index of surgical quality, has drawn increasing attention from surgeons. ${ }^{19}$ URO is typically associated with a more complicated postoperative course, particularly for complex surgical 
Table 2 Univariate analysis of potential influencing factors for URO

\begin{tabular}{|c|c|c|c|}
\hline Variables & $\begin{array}{l}\text { Non-URO } \\
\text { group } \\
(\mathrm{n}, \%)\end{array}$ & $\begin{array}{l}\text { URO } \\
\text { group } \\
(n, \%)\end{array}$ & $P$-value \\
\hline Gender & & & $0.005 *$ \\
\hline Male & $2,068(73.5)$ & $36(92.3)$ & \\
\hline Female & $745(26.5)$ & $3(7.7)$ & \\
\hline Age (years) & & & 0.088 \\
\hline$<60$ & $972(34.6)$ & $8(20.5)$ & \\
\hline$\geq 60$ & I,84I (65.4) & $31(79.5)$ & \\
\hline BMI $\left(\mathrm{kg} / \mathrm{m}^{2}\right)$ & & & 0.094 \\
\hline$\leq 25$ & $2,315(82.3)$ & $28(7 \mathrm{I} .8)$ & \\
\hline$>25$ & $498(17.7)$ & II (28.2) & \\
\hline Concomitant diseases & & & 0.700 \\
\hline No & $2,174(77.3)$ & $29(74.4)$ & \\
\hline Yes & $639(22.7)$ & $10(25.6)$ & \\
\hline Diabetes & & & $0.010 *$ \\
\hline No & $2,680(95.3)$ & $33(84.7)$ & \\
\hline Yes & $133(4.7)$ & $6(15.3)$ & \\
\hline Preoperative hypoproteinemia & & & $0.035 *$ \\
\hline No & $2,500(88.9)$ & 30 (76.9) & \\
\hline Yes & $313(11.1)$ & $9(23.1)$ & \\
\hline Preoperative anemia & & & 0.424 \\
\hline No & $\mathrm{I}, 256(44.6)$ & $20(51.3)$ & \\
\hline Yes & $\mathrm{I}, 557(55.4)$ & $19(48.7)$ & \\
\hline Tumor size $(\mathrm{cm})$ & & & 0.480 \\
\hline$\leq 5.0$ & I,986 (70.6) & 30 (76.9) & \\
\hline$>5.0$ & $827(29.4)$ & $9(23.1)$ & \\
\hline Type of reconstruction & & & 0.146 \\
\hline Roux-en-Y & $979(34.8)$ & $19(48.7)$ & \\
\hline Billroth-I & $552(19.6)$ & $3(7.7)$ & \\
\hline Billroth-II & 991 (35.2) & $12(30.8)$ & \\
\hline Esophagogastrostomy & $291(10.4)$ & $5(12.8)$ & \\
\hline Type of surgical resection & & & 0.120 \\
\hline Total & $979(34.8)$ & $19(48.7)$ & \\
\hline Distal & $\mathrm{I}, 543(54.8)$ & $15(38.5)$ & \\
\hline Proximate & $291(10.4)$ & $5(12.8)$ & \\
\hline Surgical approach & & & 0.236 \\
\hline Open & $2,234(79.4)$ & $28(71.8)$ & \\
\hline Laparoscopic & $579(20.6)$ & II (28.2) & \\
\hline Combined organ resection & & & 0.648 \\
\hline No & $2,714(96.5)$ & $37(94.9)$ & \\
\hline Yes & $99(3.5)$ & $2(5.1)$ & \\
\hline Neoadjuvant chemotherapy & & & 0.262 \\
\hline No & $\mathrm{I}, 270(45 . \mathrm{I})$ & 14 (35.9) & \\
\hline Yes & I,543 (54.9) & $25(64.1)$ & \\
\hline AJCC stage & & & 0.130 \\
\hline I & $210(7.5)$ & $4(10.3)$ & \\
\hline II & $762(27.1)$ & $5(12.8)$ & \\
\hline III & I,84I (65.4) & $30(76.9)$ & \\
\hline
\end{tabular}

Notes: $* P<0.05$. Fisher's exact test was used to calculate the $P$-value.

Abbreviations: URO, unplanned reoperation; BMI, body mass index; AJCC, American Joint Committee on Cancer.

procedures such as gastric resection. Knowledge regarding the risk factors and indications for URO could provide valuable insight. In this study, we elucidated the causes, risk factors, early outcomes, and long-term cancer-specific
Table 3 Multivariate logistic regression analysis of risk factors for URO

\begin{tabular}{|c|c|c|c|}
\hline \multirow[t]{2}{*}{ Variables } & \multicolumn{3}{|c|}{$\begin{array}{l}\text { Multivariate logistic regression } \\
\text { analysis }\end{array}$} \\
\hline & OR & $95 \% \mathrm{Cl}$ & $P$-value \\
\hline Gender & 4.630 & $1.412-15.152$ & $0.01 I^{*}$ \\
\hline Age & 1.367 & $0.452-4.136$ & 0.579 \\
\hline BMI & 1.409 & $0.485-4.095$ & 0.529 \\
\hline Concomitant diseases & $\mathrm{I} .540$ & $0.480-4.941$ & 0.467 \\
\hline Diabetes & 4.189 & $1.705-10.290$ & $0.002^{*}$ \\
\hline Preoperative hypoproteinemia & 2.305 & $1.079-4.923$ & $0.031^{*}$ \\
\hline Preoperative anemia & 0.798 & $0.334-1.903$ & $0.61 \mathrm{I}$ \\
\hline Tumor size & 1.357 & $0.423-4.355$ & 0.608 \\
\hline Type of reconstruction & 1.046 & $0.230-4.765$ & 0.954 \\
\hline Type of surgical resection & 0.465 & $0.180-1.201$ & 0.114 \\
\hline Surgical approach & 0.935 & $0.345-2.533$ & 0.896 \\
\hline Combined organ resection & 0.856 & $0.233-3.143$ & 0.814 \\
\hline Neoadjuvant chemotherapy & 1.387 & $0.153-12.566$ & $0.77 \mid$ \\
\hline Postoperative AJCC stage & $1.46 \mathrm{I}$ & $0.356-6.002$ & 0.599 \\
\hline
\end{tabular}

survival of URO after radical gastrectomy for GC. Notably, URO was found not to be correlated with the long-term cancer-specific survival according to our data.

In recent years, the incidence of URO has declined over the past years with the rapid development of surgical techniques. According to Sah et al's study, URO incidence after open gastrectomy for GC is $2.2 \%$, and the primary causes of URO are intra-abdominal bleeding and anastomotic leakage. ${ }^{20} \mathrm{Li}$ et al reported that the morbidity of patients undergoing URO after laparoscopic gastrectomy is $1.1 \%$, and the main reasons for URO are intra-abdominal hemorrhage and anastomotic bleeding. ${ }^{21}$ This study enrolled a much larger population and suggested that the URO incidence was $1.4 \%$, with intra-abdominal bleeding and anastomotic leakage being the major causes. In addition, our data showed that intra-abdominal bleeding was the most common complication after gastrectomy.

Table 4 Early surgical outcomes for patients with or without URO

\begin{tabular}{llll}
\hline Parameters & $\begin{array}{l}\text { Non-URO group } \\
(\mathbf{n}=\mathbf{2 , 8 1 3})\end{array}$ & $\begin{array}{l}\text { URO group } \\
(\mathbf{n}=\mathbf{3 9})\end{array}$ & P-value \\
\hline $\begin{array}{l}\text { Hospital stay (days) } \\
\text { Postoperative }\end{array}$ & $\begin{array}{l}15.52 \pm 6.16 \\
423(15.0 \%)^{\mathrm{a}}\end{array}$ & $\begin{array}{l}35.03 \pm 14.85 \\
19(48.7 \%)^{\mathrm{b}}\end{array}$ & $<0.00 I^{*}$ \\
$\begin{array}{l}\text { complications } \\
\text { Mortality rate }\end{array}$ & $6(0.2 \%)^{\mathrm{a}}$ & $5(12.8 \%)^{\mathrm{b}}$ & $<0.00 I^{*}$ \\
\hline
\end{tabular}

Notes: $* P<0.05$. aParameters in the non-URO group refer to data after the initial operation. 'PParameters in the URO group refer to data after the second operation. Abbreviation: URO, unplanned reoperation. 


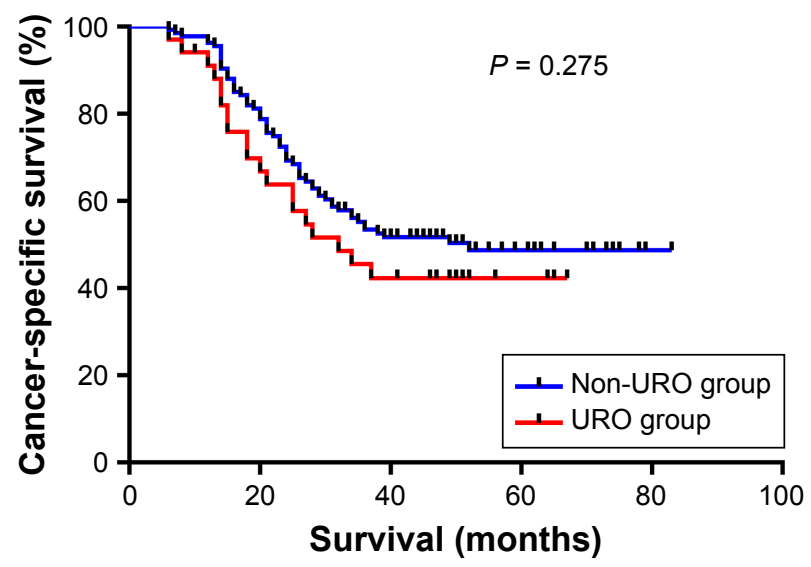

Figure 2 Kaplan-Meier curves for cancer-specific survival. Abbreviation: URO, unplanned reoperation.

Previous studies indicated that early postoperative bleeding is associated with surgeons' technical failure, ${ }^{12,22}$ such as lack of experience in the procedure of hemostasis and vessel ligatures, and anastomotic bleeding. Abdominal arterial bleeding usually occurs in splenic artery, hepatic artery, and gastroduodenal artery, with the incidence ranging from $0.6 \%$ to $3.3 \%$, and the main reason for hemorrhage was anastomotic leakage. ${ }^{23,24}$ Esophagojejunal anastomotic leakage after total gastrectomy and Roux-en-Y reconstruction was the primary reason for delayed massive abdominal bleeding. Severe postoperative hemorrhage was an extremely intractable complication which lacks standardized treatment, leading to high postoperative mortality. ${ }^{4,8}$ In this study, three out of eight re-bleeding patients died of DIC, while the remaining patients eventually recovered after one or more transcatheter arterial embolizations (TAEs) and/or surgical operations. Early postoperative arterial bleeding can be managed effectively by immediate re-laparotomy, with a satisfactory clinical outcome. ${ }^{25}$ However, relaparotomy is often difficult to perform in the latter phase as the bleeding site is hard to find due to intraperitoneal adhesion and inflammatory reaction. Alternatively, TAE is a less invasive approach, irrespective of tissue adhesion and edema caused by the initial surgery. Nevertheless, TAE had a higher re-bleeding rate compared to re-laparotomy. ${ }^{26,27}$ In case radiological intervention fails, immediate shift to surgical treatment is compulsory. ${ }^{28,29}$

As URO can cause great harm to patients, it is crucial for surgeons to evaluate the risk factors for URO before surgery, which might assist surgeons in preventing URO. Several risk factors for URO after radical gastrectomy proposed by previous studies were not completely coincident. According to Yi et al's report, ${ }^{5}$ tumor size and type of operation are risk factors for URO. One study performed by Oh et al suggested that male gender and increased mean age are closely correlated with the incidence of URO. ${ }^{4}$ Consistently, Li et al indicated that there are more elderly, male, and overweight patients in the URO group. ${ }^{21}$ In this study, we found that male gender, diabetes, and preoperative hypoproteinemia were independent risk factors for URO.

Additionally, we suggested that URO might have no impact on the long-term cancer-specific survival of the patients after radical gastrectomy, though URO impaired the early surgical outcomes. Several studies concluded that intraoperative blood loss, TNM stage, operation duration, and neoadjuvant chemotherapy are prognostic factors for patient survival. ${ }^{30}$ Nakauchi et al found that tumor size, pathological $\mathrm{N}$ factor $\geq 2$, and postoperative pancreatic fistula combined with intra-abdominal abscesses are associated with the 3-year recurrence free survival. ${ }^{31}$ This study suggested that there was no significant relationship between URO and long-term cancer-specific survival. Given that the occurrence of URO is multifactorial, we conducted a matched follow-up study to minimize the potential effect of these confounding variables. The patients from the URO group and the nonURO group were 1:4 propensity score matched according to multiple clinicopathological characteristics. Multivariate Cox analysis revealed that TNM stage III and preoperative hypoproteinemia were significant unfavorable prognostic factors for cancer-specific survival, further confirming the robustness and reliability of our results.

In spite of our efforts to conduct a comprehensive and accurate analysis, there were still several limitations in this study. First, the clinical characteristics of the Asian population may result in potential selection bias which limits its universal value. Our findings should be considered valid in the geographical-ethnical-social context and need to be verified in different populations with different phenotypes. Second, this was a retrospective study performed in a single center. Large multicenter prospective studies are duly warranted to further verify our results. Third, despite the large total sample size in this study, the sample size of URO patients was relatively small because of the low incidence of URO. Fourth, due to disparities among the treatment strategies of patients and intricate complications, potential bias might affect our results. Therefore, multi-institutional prospective cohort studies are needed for further confirmation. However, this study included a larger population than previous pertinent research, and the follow-up data were analyzed to evaluate the long-term survival of URO patients for the first time. 
Table 5 Prognostic factors for cancer-specific survival after curative gastric cancer resection in univariate and multivariable analyses

\begin{tabular}{|c|c|c|c|c|c|}
\hline \multirow[t]{3}{*}{ Prognostic factors } & \multicolumn{5}{|c|}{ Cancer-specific survival } \\
\hline & \multicolumn{3}{|l|}{ Univariate } & \multicolumn{2}{|l|}{ Multivariate } \\
\hline & Log-rank & $P$-value & HR & $95 \% \mathrm{Cl}$ & $P$-value \\
\hline \multicolumn{6}{|l|}{ URO } \\
\hline No & 1.193 & 0.275 & 1.683 & $0.923-3.071$ & 0.090 \\
\hline \multicolumn{6}{|l|}{ Yes } \\
\hline \multicolumn{6}{|l|}{ Gender } \\
\hline Female & 0.200 & 0.655 & 0.853 & $0.460-1.852$ & 0.615 \\
\hline \multicolumn{6}{|l|}{ Male } \\
\hline \multicolumn{6}{|l|}{ Age (years) } \\
\hline$<60$ & 0.822 & 0.365 & 1.049 & $0.585-1.882$ & 0.873 \\
\hline \multicolumn{6}{|l|}{$\geq 60$} \\
\hline \multicolumn{6}{|l|}{ BMI } \\
\hline$\leq 25$ & 1.032 & 0.310 & I.I87 & $0.68 \mathrm{I}-2.067$ & 0.546 \\
\hline \multicolumn{6}{|l|}{$>25$} \\
\hline \multicolumn{6}{|l|}{ Concomitant diseases } \\
\hline No & 0.147 & $0.70 \mathrm{I}$ & 0.979 & $0.523-1.833$ & 0.947 \\
\hline \multicolumn{6}{|l|}{ Yes } \\
\hline \multicolumn{6}{|l|}{ Diabetes } \\
\hline No & 0.656 & 0.418 & 0.718 & $0.272-1.892$ & 0.502 \\
\hline \multicolumn{6}{|l|}{ Yes } \\
\hline \multicolumn{6}{|c|}{ Preoperative hypoproteinemia } \\
\hline No & 4.757 & $0.029 *$ & 1.831 & $1.126-2.978$ & $0.015^{*}$ \\
\hline \multicolumn{6}{|l|}{ Yes } \\
\hline \multicolumn{6}{|l|}{ Anemia } \\
\hline No & 3.650 & 0.056 & 1.415 & $0.878-2.281$ & 0.153 \\
\hline \multicolumn{6}{|l|}{ Yes } \\
\hline \multicolumn{6}{|l|}{ Tumor size $(\mathrm{cm})$} \\
\hline$<5$ & 0.016 & 0.900 & 0.978 & $0.533-1.793$ & 0.942 \\
\hline \multicolumn{6}{|l|}{$\geq 5$} \\
\hline \multicolumn{6}{|l|}{ AJCC stage } \\
\hline 1 & 17.920 & $<0.00 I^{*}$ & Reference & & \\
\hline II & & & 2.575 & $0.631-10.510$ & 0.187 \\
\hline III & & & 7.004 & $2.130-23.034$ & $0.00 I^{*}$ \\
\hline \multicolumn{6}{|l|}{ Surgical approach } \\
\hline Open & 2.522 & 0.118 & 0.893 & $0.549-1.454$ & 0.649 \\
\hline Laparoscopic & & & & & \\
\hline Type of reconstructio & & & & & \\
\hline Billroth-I & 0.023 & 0.878 & 0.716 & $0.420-1.219$ & 0.219 \\
\hline Billroth-II & & & & & \\
\hline Roux-en-Y & & & & & \\
\hline Esophagogastrostor & & & & & \\
\hline Combined organ rese & & & & & \\
\hline No & $\mathrm{I} .48 \mathrm{I}$ & 0.224 & 0.311 & $0.038-2.526$ & 0.274 \\
\hline Yes & & & & & \\
\hline
\end{tabular}

Note: $* P<0.05$.

Abbreviations: URO, unplanned reoperation; BMI, body mass index; AJCC, American Joint Committee on Cancer.

\section{Conclusion}

This study suggests that male gender, diabetes, and preoperative hypoproteinemia might be risk factors for URO after gastrectomy for GC. URO was associated with increased time of hospital stay and higher perioperative mortality but might not be correlated with long-term survival. These findings may assist in the identification of patients at high risk for URO that may benefit from preoperative counseling, optimization, and tailoring of postoperative management to reduce the rate of reoperation.

\section{Acknowledgments}

This study was funded by the Natural Science Research of Anhui Education Department Key Project (No. KJ2018A0246) and Anhui Natural Science Foundation (No.1508085MH147). 


\section{Disclosure}

The authors report no conflicts of interest in this work.

\section{References}

1. Global Burden of Disease Cancer Collaboration, Fitzmaurice C, Allen C, et al. Global, regional, and national cancer incidence, mortality, years of life lost, years lived with disability, and disability-adjusted life-years for 32 cancer groups, 1990 to 2015: A systematic analysis for the global burden of disease study. JAMA Oncol. 2017;3(4):524-548.

2. Yang L. Incidence and mortality of gastric cancer in China. World $J$ Gastroenterol. 2006;12(1):17-20.

3. Pedrazzani C, Marrelli D, Rampone B, et al. Postoperative complications and functional results after subtotal gastrectomy with Billroth II reconstruction for primary gastric cancer. Dig Dis Sci. 2007;52(8): $1757-1763$.

4. Oh SJ, Choi WB, Song J, et al. Complications requiring reoperation after gastrectomy for gastric cancer: 17 years experience in a single institute. J Gastrointest Surg. 2009;13(2):239-245.

5. Yi HW, Kim SM, Kim SH, et al. Complications leading reoperation after gastrectomy in patients with gastric cancer: frequency, type, and potential causes. J Gastric Cancer. 2013;13(4):242-246.

6. Ferlay J, Shin HR, Bray F, et al. Estimates of worldwide burden of cancer in 2008: GLOBOCAN 2008. Int J Cancer. 2010;127(12):2893-2917.

7. Selby LV, Gennarelli RL, Schnorr GC, et al. Association of hospital costs with complications following total gastrectomy for gastric adenocarcinoma. JAMA Surg. 2017;152(10):953-958.

8. Tu RH, Lin JX, Zheng CH, et al. Complications and failure to rescue following laparoscopic or open gastrectomy for gastric cancer: a propensity-matched analysis. Surg Endosc. 2017;31(5):2325-2337.

9. Trakulthong C, Phunmanee A. Mortality risk factors during readmission at the Department of Medicine. Ther Clin Risk Manag. 2017;13: 1551-1554.

10. Deguchi Y, Fukagawa T, Morita S, et al. Identification of risk factors for esophagojejunal anastomotic leakage after gastric surgery. World J Surg. 2012;36(7):1617-1622.

11. Chen JH, Cai SR, Zhai ET, et al. Survival prognosis and clinicopathological features of the lymph nodes along the left gastric artery in gastric cancer: implications for D2 lymphadenectomy. Int J Clin Exp Pathol. 2015;8(11):14365-14373.

12. De Angelis F, Abdelgawad M, Rizzello M, Mattia C, Silecchia G. Perioperative hemorrhagic complications after laparoscopic sleeve gastrectomy: four-year experience of a bariatric center of excellence. Surg Endosc. 2017;31(9):3547-3551.

13. Kobayashi N, Shinohara H, Haruta S, et al. Process of pancreas head as a risk factor for postoperative pancreatic fistula in laparoscopic gastric cancer surgery. World J Surg. 2016;40(9):2194-2201.

14. Ikoma N, Blum M, Estrella JS, et al. Evaluation of the American Joint Committee on Cancer 8th edition staging system for gastric cancer patients after preoperative therapy. Gastric Cancer. 2018;21(1):74-83.

15. Van Laethem JL, Carneiro F, Ducreux M, et al. The multidisciplinary management of gastro-oesophageal junction tumours: European Society of Digestive Oncology (ESDO): Expert discussion and report from the 16th ESMO World Congress on Gastrointestinal Cancer, Barcelona. Dig Liver Dis. 2016;48(11):1283-1289.

Therapeutics and Clinical Risk Management

\section{Publish your work in this journal}

Therapeutics and Clinical Risk Management is an international, peerreviewed journal of clinical therapeutics and risk management, focusing on concise rapid reporting of clinical studies in all therapeutic areas, outcomes, safety, and programs for the effective, safe, and sustained use of medicines. This journal is indexed on PubMed Central, CAS,
16. Japanese Gastric Cancer Association. Japanese gastric cancer treatment guidelines 2010 (ver. 3). Gastric Cancer. 2011;14(2):113-123.

17. Ebinger SM, Warschkow R, Tarantino I, Schmied BM, Marti L. Anastomotic leakage after curative rectal cancer resection has no impact on long-term survival: a propensity score analysis. Int J Colorectal Dis. 2015;30(12):1667-1675.

18. Kroon HM, Breslau PJ, Lardenoye JW. Can the incidence of unplanned reoperations be used as an indicator of quality of care in surgery? Am J Med Qual. 2007;22(3):198-202.

19. Michaels AD, Mullen MG, Guidry CA, et al. Unplanned reoperation following colorectal surgery: indications and operations. J Gastrointest Surg. 2017;21(9):1480-1485.

20. Sah BK, Chen MM, Yan M, Zhu ZG. Reoperation for early postoperative complications after gastric cancer surgery in a Chinese hospital. World J Gastroenterol. 2010;16(1):98-103.

21. Li P, Huang CM, Tu RH, et al. Risk factors affecting unplanned reoperation after laparoscopic gastrectomy for gastric cancer: experience from a high-volume center. Surg Endosc. 2017;31(10):3922-3931.

22. Khoursheed M, Al-Bader I, Mouzannar A, et al. Postoperative bleeding and leakage after sleeve gastrectomy: a single-center experience. Obes Surg. 2016;26(12):3007.

23. Kodera Y, Sasako M, Yamamoto S, et al. Identification of risk factors for the development of complications following extended and superextended lymphadenectomies for gastric cancer. Br J Surg. 2005; 92(9):1103-1109.

24. Mita K, Ito H, Murabayashi R, et al. Postoperative bleeding complications after gastric cancer surgery in patients receiving anticoagulation and/or antiplatelet agents. Ann Surg Oncol. 2012;19(12):3745-3752.

25. Park JY, Kim YW, Eom BW, et al. Unique patterns and proper management of postgastrectomy bleeding in patients with gastric cancer. Surgery. 2014;155(6):1023-1029.

26. Spivak H, Azran C, Spectre G, Lidermann G, Blumenfeld O. Sleeve gastrectomy postoperative hemorrhage is linked to type-2 diabetes and not to surgical technique. Obes Surg. 2017;27(11):2927-2932.

27. Yap FY, Omene BO, Patel MN, et al. Transcatheter embolotherapy for gastrointestinal bleeding: a single center review of safety, efficacy, and clinical outcomes. Dig Dis Sci. 2013;58(7):1976-1984.

28. Jilesen AP, Tol JA, Busch OR, et al. Emergency management in patients with late hemorrhage after pancreatoduodenectomy for a periampullary tumor. World J Surg. 2014;38(9):2438-2447.

29. Han K, Ahmed BM, Kim MD, et al. Clinical outcome of transarterial embolization for postgastrectomy arterial bleeding. Gastric Cancer. 2017;20(5):887-894.

30. Wang L, Wang XA, Hao JQ, et al. Long-term outcomes after radical gastrectomy in gastric cancer patients with overt bleeding. World $J$ Gastroenterol. 2015;21(47):13316-13324.

31. Nakauchi M, Suda K, Kadoya S, et al. Technical aspects and shortand long-term outcomes of totally laparoscopic total gastrectomy for advanced gastric cancer: a single-institution retrospective study. Surg Endosc. 2016;30(10):4632-4639.

\section{Dovepress}

EMBase, Scopus and the Elsevier Bibliographic databases. The manuscript management system is completely online and includes a very quick and fair peer-review system, which is all easy to use. Visit http://www.dovepress.com/testimonials.php to read real quotes from published authors. 